Disclosure of Interest: None declared

DOI: 10.1136/annrheumdis-2018-eular.5156

\section{THU0748-HPR EVALUATION OF ADHERENCE TO BIOLOGIC DISEASE MODIFYING ANTI-RHEUMATIC DRUGS IN PATIENTS WITH INFLAMMATORY ARTHRITIS}

Y.C. Lim ${ }^{1}$, W.G. Teo ${ }^{2}$, M.N. Eng ${ }^{1}$, H.M. Cheen ${ }^{1}$, X.Y. Tay ${ }^{1}$, S.I. Yeo ${ }^{3}$, T.G. Lim ${ }^{1}$. ${ }^{1}$ Pharmacy, Singapore General Hospital, ${ }^{2}$ Pharmacy, National Heart Centre Singapore; ${ }^{3}$ Rheumatology and Immunology, Singapore General Hospital, Singapore, Singapore

Background: In recent years, bDMARDs have revolutionised IA treatment in improving IA symptoms, as well as slowing down structural damage. However, efficacy observed in the controlled settings of clinical trials may not always translate to effectiveness in clinical practice. ${ }^{12}$ Currently, there are no published studies assessing adherence to bDMARDs and its associated factors among IA patients in Singapore. Knowledge of the extent of poor adherence to bDMARDs and its risk factors can facilitate efficient implementation of interventions to improve adherence and IA outcomes.

Objectives: The primary objective of the study was to assess adherence to bDMARDs among patients with IA in Singapore. The secondary objective was to identify factors associated with poor adherence to bDMARDs.

Methods: A retrospective observational study was conducted at Singapore General Hospital, a 1600-bed academic medical centre. Electronic records of patients diagnosed with rheumatoid arthritis (RA), spondyloarthritis $(\mathrm{SpA})$ or psoriatic arthritis (PsA) who had received at least six consecutive months of bDMARDs between 1 st January 2010 and 31 st December 2015 were reviewed. Adherence was calculated by proportion of days covered (PDC) using the following formula: $\mathrm{PDC}=\left[\sum\right.$ (number of doses $\times$ prescribed frequency) $]$ (total duration) $\times 100 \%$. Patients with PDC $>0.80$ were considered adherent. ${ }^{3}$ Factors associated with adherence to bDMARDs were identified using multivariate logistic regression using the entire dataset and then by type of IA.

Results: Among 115 patients included in the analyses, majority of the patients were Chinese $(n=77,67 \%)$ and females $(n=61,53 \%)$. Other pertinent demographics and clinical characteristics are detailed in table 1. The mean PDC was $0.82( \pm 0.18)$ and $69(60 \%)$ patients were adherent (i.e. $P D C \geq 0.8)$. Multivariate logistic regression did not identify any factors significantly associated with adherence. Patients with SpA who previously received a bDMARD $(\mathrm{OR}=5.12 ; 95 \% \mathrm{Cl}$ $1.02-25.8 ; \mathrm{p}=0.048)$ and who did not receive subsidy $(\mathrm{OR}=0.21 ; 95 \% \mathrm{Cl} 0.50$ $0.89 ; p=0.034$ ) were found to be significantly associated with adherence.

Abstract THU0748HPR - Table 1. Patient demographics and clinical characteristics

\begin{tabular}{lcc}
\hline Characteristics $(\mathbf{n}=\mathbf{1 1 5})$ & $\mathrm{n},(\%)$ unless indicated \\
\hline Mean age at bDMARD initiation, years $(\mathbf{( S D})$ & Male & $45.5( \pm 12.0)$ \\
Gender & Female & $54(47.0)$ \\
& Chinese & $61(53.0)$ \\
Race & Indian & $77(67.0)$ \\
& Malay & $17(14.8)$ \\
& Others & $9(7.8)$ \\
Diagnosis & RA & $12(10.4)$ \\
& SpA & $45(39.0)$ \\
Biologic Naïve & PsA & $44(38.0)$ \\
& Yes & $26(23.0)$ \\
Current Biologic & No & $79(68.7)$ \\
& TNFi & $36(31.3)$ \\
& Non-TNFi & $101(87.8)$ \\
& & $14(12.2)$ \\
\hline
\end{tabular}

Conclusions: The findings of this study suggest that IA patients have suboptimal adherence to bDMARDs. Determinants of poor adherence remain elusive and further research into the social, psychological and environmental aspects is warranted. Measures to improve affordability of bDMARDs such as obtaining government subsidies and offering patient access schemes may improve adherence as seen in patients with $\mathrm{SpA}$.

\section{REFERENCES:}

[1] Harnett J, et al. J Manag Care Spec Pharm. 2016;22(3):209-18.

[2] Koncz T, et al. Expert Opin. Biol. Ther. 2010;10(9):1367-1378.

[3] Choudhry NK, et al. Am J Manag Care 2009 July;15(7):457-464.
FRIDAY, 15 JUNE 2018

HPR Patients' perspectives, functioning and health (descriptive: qualitative or quantitative)

\section{FRI0702-HPR TREATMENT SATISFACTION IN PATIENTS WITH JUVENILE IDIOPATHIC ARTHRITIS}

A. Tollisen ${ }^{1}$, A.M. Selvaag ${ }^{1}$, T. Ingebrigtsen ${ }^{1}$, A. Aasland ${ }^{2}$, A. Lerdal ${ }^{3}$, B. Flatø ${ }^{1}$. ${ }^{1}$ Department of Rheumatology; ${ }^{2}$ Department of Clinical Neurosciences for Children, Rikshospitalet, Oslo University Hospital; ${ }^{3}$ Department of Research, Lovisenberg Diaconal Hospital, Oslo, Norway

Background: Limited information exists regarding treatment satisfaction in patients with Juvenile Idiopathic Arthritis (JIA).

Objectives: The aim of this study was to investigate satisfaction with synthetic and biologic disease-modifying anti-rheumatic drugs (sDMARDs and bDMARDs) in adults with JIA.

Methods: Patients with JIA who attended Oslo University Hospital from 19952000 with $<18$ months disease duration were invited to participate. From a cohort of 96 patients, 52 (54\%) used DMARDs. Patients treated with Methotrexate (MTX) or biologics were assessed with the 14-item Treatment Satisfaction Questionnaire for Medication (TSQM, one questionnaire for each medication). The TSQM covers 4 domains (effectiveness, side effects, convenience and global satisfaction) with a score range from $0-100$ and with higher score representing higher satisfaction on the domain.

Results: The mean age of the 52 participants was 25.1 (4.6) years, 75\% were female and $33(63 \%)$ patients had polyarticular couse JIA. The following DMARDs were used; MTX $(n=29)$, biologics $[n=37$ (etanercept, $n=13$; adalimumab, $n=8$; tocilizumab, $n=6$; infliximab, $n=3$; certolizumab, $n=3$; golimumab, $n=2$; anakinra $\mathrm{n}=1$ and rituximab, $\mathrm{n}=1)$ ] and sulfasalazine $(\mathrm{n}=5) .19$ patients used a combination of sDMARDs and bDMARDs or 2 sDMARDs.

\begin{tabular}{lll}
\hline Clinical characteristics & All patients $(\mathrm{N}=96)$ & Patients on DMARDs $(\mathrm{n}=52)$ \\
\hline Disease duration, years, mean (SD) & $18.9(1.5)$ & $18.7(1.6)$ \\
Age at disease onset, years, mean (SD) & $6.1(4.0)$ & $6.3(4.4)$ \\
ILAR classification, $\mathrm{n}(\%)$ & & \\
Systemic arhtitis & $7(7)$ & $2(4)$ \\
Polyarticular RF negative & $24(25)$ & $16(31)$ \\
Plyarticular RF positive & $1(1)$ & $1(2)$ \\
Oligoarticular persistent & $36(38)$ & $13(25)$ \\
Oligoarticular extended & $10(10)$ & $7(13)$ \\
Enthesitis-related arthritis & $5(5)$ & $2(4)$ \\
Psoriatic arthritis & $4(4)$ & $4(8)$ \\
Undifferenciated arthritis & $9(9)$ & $7(13)$
\end{tabular}

Undifferenciated arthritis

$9(9)$

\begin{tabular}{llll}
\hline $\begin{array}{l}\text { TSQM domains, mean } \\
\text { (SD) }\end{array}$ & $\begin{array}{l}\text { MTX } \\
(\mathrm{n}=29)\end{array}$ & $\begin{array}{l}\text { Biologics } \\
(\mathrm{n}=37)\end{array}$ & P-value \\
\hline Effectiveness & $59.8(19.6)$ & $74.2(15.5)$ & 0.002 \\
Side effects & $62 .(30.1)$ & $90.1(20.5)$ & $<0.001$ \\
Convenience & $64.3(22.1)$ & $69.1(13.3)$ & 0.282 \\
Global satisfaction & $48.5(23.1)$ & $70.4(18.9)$ & $<0.001$ \\
\hline
\end{tabular}

A correlation was found between the domain side effects and age in patients using MTX (rs 0.368, p=0.049). No other associations were found between TSQM domains and age, gender, disease duration or polyarticular disease course.

Conclusions: Patients reported higher treatment satisfaction with biologics compared to MTX in the domains effectiveness, side effects and global satisfaction. An association was found between age and the TSQM domain side effects in patients using MTX. Other domains of TSQM were not related to patient or disease characteristics in JIA. In order to ensure good health care, information of patients' treatment satisfaction should be incorporated in the process of treatment decision-making.

Acknowledgements: This project was supported by the Norwegian Foundation for Health and Rehabilitation

Disclosure of Interest: None declared

DOI: 10.1136/annrheumdis-2018-eular.6477

Disclosure of Interest: None declared

DOI: 10.1136/annrheumdis-2018-eular.2183 